\title{
Слово ПРЕДОСТАВЛЯЕТСЯ
}

УДК 37.01

DOI: 10.31862/1819-463X-2020-5-198-203

ББК 74.03(2)

\section{ХУДОЖЕСТВЕННО-ПРОМЫШЛЕННЫЕ УЧЕБНЫЕ ЗАВЕДЕНИЯ ГЖЕЛИ В 1937-1948 ГГ.}

\section{Э. К. Сухова, И. В. Сидоров}

Аннотация. $B$ статье на основе новых обнаруженных источников анализируется развитие художественно-промышленного образования на территории бытования Гжельского народного прольсла в предвоенные, военные и послевоенные годь. Показано, что подготовка кадров для прольсла не илела длительного перерыва в указываемый период, как это считалось ранее, и обсуждаются дальнейшие перспективь исследований вопроса.

Ключевые слова: художественно-промышленное образование, народный прольсел, Гжель, история образования.

\section{GZHEL ART AND INDUSTRY EDUCATION INSTITUTIONS IN 1937-1948.}

\section{E. K. Sukhova, I. V. Sidorov}

Abstract. The article analyzes the development of artistic and industrial education in the territory of Gzhel craftsmanship in the pre-war, war and post-war years on the basis of newly discovered sources. It shows that training for folk crafts did not have a long break in the period in question, as previously thought, and discusses further prospects for research into the issue.

Keywords: art and industrial education, folk craft, Gzhel, history of education.

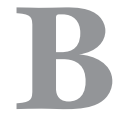

плоть до настоящего времени в истории художественно-промышленного образования Гжели оставался малоизученным период между 1937 и 1944 г. между прекращением и возобновлением деятельности Гжельского техникума соответственно. Это объясняется как недостатком доступных исследователям документальных подтверждений, так и весьма неконкретным содержанием имеющихся в на-

() Сухова Э. К., Сидоров И. В., 2020 
учном обороте свидетельств. Они указывали на полное отсутствие в эти годы на гжельском промысле художественно-промышленного образования как такового.

Так, одним из последних упоминаний техникума в источниках является датируемый 1941 г. отчет о командировке сотрудника научно-исследовательского института художественной промышленности (НИИХП) Дзагурова [1]. Направленный в Гжель с проверкой деятельности местных артелей, он констатировал деградацию творческого уровня промысла, вызванную в том числе отсутствием квалифицированного художественного руководства, и в этой связи, среди прочего, упомянул Гжельский техникум как выбывший в 1937 г. в Ленинград. Этот документ служил главным и единственным аргументом в пользу версии о перерыве в традиции художественно-промышленного образования Гжели в связи с переводом ее единственного на тот момент носителя - техникума.

Однако производившиеся научными сотрудниками ГГУ запросы в архивы СанктПетербурга не принесли каких-либо документальных подтверждений этому предположению. Неоднозначность ситуации состояла также и в том, что следующее обнаруженное в архивах упоминание о техникуме относится уже к 1944 г., когда техникум «возобновил деятельность» (а эта формулировка предполагает, что некий период времени он реально отсутствовал) [2, с. 334]. Еще одним косвенным свидетельством произошедших в 1937 г. изменений является обнаруженная в частном архиве семьи выпускницы Гжельского керамического техникума 1935 г. Людмилы Фёдоровны Троицкой справка от 1 августа 1937 г., из которой явствует, что Л. Ф. Троицкая работала в Гжельском керамическом техникуме в качестве лаборанта химлаборатории с 20 августа 1935 г. по 29 августа 1937 г. и была освобождена от работы ввиду реорганизации техникума.

Ввод в научный оборот новых свидетельств, обнаруженных авторами, позволяет утверждать, что самобытная традиция художественно-промышленного образования, развивавшаяся на гжельской земле с
1899 г., в эти годы все же полностью не прерывалась. Достаточно многочисленные (хотя и микроисторического свойства) подтверждения были обнаружены в районной прессе тех лет и собственном архиве Гжельского госуниверситета. Ключевым источником здесь является ежедневная газета $\mathrm{Pa}$ менского горкома ВКП(б) «Авангард».

Ее материалы подтверждают и то, что в 1937 г. Гжельский техникум еще действовал (так, в год столетия гибели А. С. Пушкина в нем проводились соответствующие мероприятия $[3,4])$ вплоть до июня месяца (есть материал об успешном выступлении учащихся техникума на районных соревнованиях [5]). В личном архиве Г. К. Навроцкой обнаружена также приуроченная к июню 1937 г. фотография очередного выпуска с преподавателями. Наконец, в номере «Авангарда» от 28 июля 1937 г. вышло объявление о реорганизации техникума в учебно-курсовую базу института повышения квалификации при Москопромсовете и установлении в связи с этим сроком окончательных расчетов по нему [6].

Таким образом, Гжельский техникум в 1937 г. был полностью переформатирован, превратившись в организацию дополнительного образования, сохранив при этом подчиненность промкооперации. Тем не менее в достаточно подробных делах ГАРФ за 1937 и 1938 г., отражающих состав и деятельность учреждений Всекопромсовета, где, по идее, должны быть упоминания и о Гжельской курсовой базе, их обнаружить не удалось [7-9]. В основном сведения о работе «Гжельской учебно-курсовой базы», а в некоторых публикациях - «Гжельского учебно-курсового комбината» представлены, опять же, в газете «Авангард», где встречаются достаточно регулярно и отличаются разносторонностью.

Так, из них следует, что обучающиеся нового заведения имели статус курсантов (а не учащихся или слушателей) и воспитывались в традиционных советских идейных установках [10]. Имеются публикации и о хозяйственных проблемах этого учебного заведения, в том числе весьма критические $[11,12]$. Из последних наиболее примечательно со- 
общение курсанта Подрочновой [13] уже от 1940 г., из которого, кроме жалобы на проблемы с питанием, следует, что комбинат продолжал свое существование и насчитывал к тому времени 250 обучающихся. Последние упоминания о его работе в местной печати относятся к весне 1941 г. [14]. Организация учебно-воспитательного процесса в тот период оценивалась современниками неудовлетворительно [15], да и прямое отношение к промыслу (а значит, и некий художественно-промышленный уклон), обучая экономическим и управленческим знаниям руководителей местных предприятий [16], он обретает также только к этому времени.

Параллельно осенью 1940 г. в Турыгине (то есть там же, где прежде находился техникум, а теперь учебно-курсовой комбинат или база) создается керамико-фарфоровая профтехшкола Мособлпромсовета, о чем в «Авангарде» выходит соответствующее объявление [17]. Данная «вновь образованная» школа также подчинялась промкооперации и имеет все основания считаться именно художественно-промышленным заведением, поскольку, судя по объявлению о приеме, в ней были открыты скульптурное и живописное отделения, а также отделения формовщиков и гончаров ручной формовки. Впрочем, никаких иных подробностей ни об учебно-воспитательном процессе, ни о хозяйственных делах этой профтехшколы ни в остаток 1940 г., ни за 1941 г. «Авангард» не сообщает. О ней умалчивают и позднейшие работы по истории промысла [18, с. 167].

История художественно-промышленных учебных заведений на Гжельском промысле в период Великой Отечественной войны не вполне прояснена. Однако некоторая реконструкция событий военных лет возможна через анализ воспоминаний местных жителей. Имеется по меньшей мере два зафиксированных свидетельства о том, что в годы Великой Отечественной войны, но не позднее 1944 г. здание бывшего Гжельского керамического техникума использовалось Красной Армией для своих нужд. Хотя качество этих свидетельств, безусловно, небесспорно [19], неточности и несовпадения лег- ко объяснимы, в частности, детским возрастом свидетелей. Главное, что сам факт присутствия военнослужащих в стенах бывшего техникума, профтехшколы и комбината зафиксирован достаточно четко. Неизвестно лишь, как именно бывший техникум использовался красноармейцами, в числе наиболее вероятных, но требующих дальнейшей проработки и документальных подтверждений версий - школа младших командиров или госпиталь, что было обычной практикой военного времени. После себя военные оставили помещения бараков, в последующем служившие учащимся техникума как общежития [20, с. 188].

Иными словами, художественно-промышленное образование Гжели, по-видимому, если и прекращается когда-либо во второй трети XX в., то лишь по объективным обстоятельствам в начальный период Великой Отечественной войны, как и вся жизнь промысла. Во всяком случае, следующее архивное упоминание о работе собственно техникума, как уже сообщалось ранее, мы встречаем лишь весной 1944 г. в виде приказа по Управлению промысловой кооперации о создании Гжельского силикатно-керамического техникума от 23.03.1944. Примечательно, что, судя по его тексту, зданием возрождаемого учебного заведения на тот момент уже распоряжались не военные, а местные власти в лице Раменского райисполкома, от которого промкооперация рассчитывала его принять (в документе это сформулировано так: «добиться от Раменского райисполкома освобождения помещения техникума к 1 апреля 1944 года» [2, с. 334]).

Апрель 1944 г. как новая точка отсчета подтверждается и воспоминаниями многолетнего преподавателя техникума и участника войны И. А. Соколова, зафиксированными в техникумовской стенгазете октября 1981 г. и перепечатанными десятью годами позднее в местной газете «Гжель» [21]. Ветеран вспоминал также, что направление на работу в техникум он получил в мае 1944 г. по выписке из госпиталя после тяжелого ранения и в течение лета вместе с остальным сформированным коллективом ремонтировал учебное 
здание к началу занятий. В газете «Авангард» выходит и соответствующее объявление [22]. Наборы в техникум с 1944 г. осуществлялись далее ежегодно без перерывов.

Однако в 1946 г., наряду с очередным объявлением о приеме в техникум, встречается отдельное объявление и о приеме в Гжельскую профтехшколу [23]. Оно позволяет судить о некоторых особенностях учебного процесса: учебное заведение работает по несколько упрощенной по сравнению с 1940 г. программе, так как теперь в нее готовы принимать лиц с образованием не ниже трех классов (против пяти в 1940 г.), а подготовка живописцев по фарфору и мастеров керамики занимала один год (против двух в 1940 г.). Более того, по некоторым данным, как минимум один выпуск Гжельской профтехшколы уже состоялся в 1945 г. [24, с. 97-98]. Однако эта информация противоречит другому источнику, утверждавшему, что первые послевоенные выпускники гжельской профтехшколы пришли на работу в артель «Художественная керамика» в 1946 г. [18, с. 39].

Как именно сосуществовали, в каком соподчинении были делившие площадь техникум и профтехшкола? Источники по этому вопросу крайне скупы, однако некоторые подсказки были обнаружены в архиве Гжельского университета.

Это, прежде всего, лишенное каких-либо реквизитов и даже заголовка предписание [25], требующее от классных руководителей техникума, руководителей кружков и воспитателя профтехшколы представить в учебную часть планы работ к 7 января 1946 г. (то есть, возможно, текст был составлен еще в конце 1945 г.). Ниже идут подписи семерых классных руководителей, троих руководителей кружков и воспитателя профтехшколы Литовой (без детализации).

Второй документ атрибутирован намного лучше. Это приказ по Гжельскому силикатнокерамическому техникуму № 18 от 2 февраля 1946 г. [26], требующий от «нижепоименованных преподавателей и сотрудников техникума и профтехшколы» предоставить не позднее 25 февраля для оформления личных дел документы по приводимому далее списку.
Оба этих свидетельства говорят об одном: профтехшкола находилась в подчинении Гжельского техникума, управляясь приказами его директора. Вопрос состоит лишь в том, являлась ли она самостоятельным юридическим лицом (например, филиалом) или была внутренним подразделением. Против последней версии говорит то, что в делах техникума имеются приказы о выпуске и протоколы квалификационных комиссий только по среднему специальному образованию.

Вообще, безотносительно к предыдущему, деятельность Гжельской профтехшколы представляет собой отдельную и достаточно важную для исследования часть истории промысла. Особое значение здесь имеет установление ее дальнейшей исторической судьбы и оценка итогов ее деятельности, так как де-факто из всех учебных заведений Гжели того периода только она работала непосредственно на благо возрождаемого народного промысла. Гжельский техникум в то время и много позже был сугубо техническим учебным заведением. Сегодня известно лишь то, что школа существовала как минимум до 1948 г., когда именно ее (а не техникум, так как это не подтверждается материалами его архива) закончил известный в будущем народный мастер-керамист В. С. Кустарев [18, с. 177].

Таким образом, новые обнаруженные свидетельства позволяют констатировать, что традиция художественно-промышленного образования в Гжели не имела длительных перерывов перед Великой Отечественной войной и в первые ее годы, как это предполагалось ранее. Более того, ранее она связывалась исключительно с работой Гжельского техникума по реализации программ среднего специального образования. Обнаруженные и введенные в научный оборот свидетельства демонстрируют существование в рассматриваемый период и другого уровня художественно-промышленного образования в Гжели - профессионально-технического. На основе анализа источников правомерно заключить, что его деятельность являлась одним из непосредственных факторов возрождения промысла. 


\section{СПИСОК ЛИТЕРАТУРЫ}

1. Дзагуров. Краткий доклад о командировке в Гжель 23-24 февраля 1941 г. // Архив ВМДПНИ. Ф. 643. Оп. 4. Д. 474.

2. Илькевич Б. В., Никонов В. В. Художественно-промышленное образование в Гжели. 1899-1937 гг. Гжель: ГГХПИ, 2014. 352 с.

3. В керамическом техникуме // Авангард. 1937. 15 янв. С. 4.

4. Вечер в керамическом техникуме // Авангард. 1937. 3 фев. С. 2.

5. Соревнования по легкой атлетике // Авангард. 1937. 9 июн. С. 4.

6. Ввиду реорганизации Гжельского керамического техникума... // Авангард. 1937. 28 июл. С. 4.

7. ГАРФ. Ф. А-262. Оп. 1. Дд. 2150, 2152, 2159, 2161, 2162.

8. ГАРФ. Ф. А-374. Оп. 15. Дд. 2215, 2216, 2218.

9. ГАРФ. Ф. 395. Оп. 1. Д. 1545.

10. 5 тысяч членов МОПРа // Авангард. 1939. 18 июн. С. 2.

11. Грубый поступок директора // Авангард. 1939. 10 окт. С. 4.

12. Нарушение трудового законодательства // Авангард. 1939. 10 окт. С. 4.

13. Нет порядка в столовой // Авангард. 1940. 30 мар. С. 2.

14. Ночное учение // Авангард. 1941. 29 апр. С. 2.

15. Беспорядки в учебном комбинате // Авангард. 1941. 19 апр. С. 2.

16. Экономическое образование актива промкооперации // Авангард. 1941. 31 мая. С. 2.

17. Вновь организованная Гжельская керамико-фарфоровая профтехшкола Мособлпромсовета объявляет набор // Авангард. 1940. 20 нояб. С. 4.

18. Логинов В. М., Скальский Ю. П. Эта звонкая сказка - Гжель. М.: Сварог, 1994. 191 с.

19. Сидоров И. В. Здание Гжельского техникума на службе защитников Москвы в 1941 году // Социогуманитарные науки и социальные технологии: перспективы, приоритеты и прогнозы: сб. науч. тр. по материалам междунар. науч.-практ. конф., 10 апр. 2019 г. СПб.: Профессиональная наука, 2019. С. 26-31.

20. Киселёв А. Г., Соловьёва С. Н., Батенчук Д. М. Учащиеся Гжельского техникума, 1947-1957 гг.: моногр. Гжель: Изд-во ГГУ, 2016. 288 с.

21. Воспоминание ветерана // Гжель. 1991. № 5-6. С. 3.

22. Объявлен прием в Гжельский силикатно-керамический техникум управления промкооперации при СНК РСФСР // Авангард. 1944. 20 авг. С. 2.

23. Гжельская профессионально-техническая школа объявляет набор // Авангард. 1946. 10 авг. (№ 120). С. 2.

24. Григорьева Н. С. Художественная керамика Гжели и Скопина в собрании Государственного Русского музея: каталог. Л.: Искусство, 1987. 150 с.

25. Архив ГГУ. Книга приказов Гжельского техникума за 1946 г. «Всем классным руководителям техникума...»

26. Архив ГГУ. Книга приказов Гжельского техникума за 1946 г.: № 18 от 02.02.1962.

\section{REFERENCES}

1. Dzagurov. Kratkiy doklad o komandirovke v Gzhel 23-24 Feb. 1941. In: Arkhiv VMDPNI. F. 643. Op. 4. D. 474.

2. Ilkevich B. V., Nikonov V. V. Khudozhestvenno-promyshlennoe obrazovanie v Gzheli. 1899-1937 gg. Gzhel: GGKhPI, 2014. 352 p.

3. V keramicheskom tekhnikume. Avangard. 1937. 15 Jan., p. 4.

4. Vecher v keramicheskom tekhnikume. Avangard. 1937, 3 Feb., p. 2.

5. Sorevnovaniya po legkoy atletike. Avangard. 1937, 9 Jun., p. 4.

6. Vvidu reorganizatsii Gzhelskogo keramicheskogo tekhnikuma... Avangard. 1937, 28 Jul., p. 4. 
7. GARF. F. A-262. Op. 1. Dd. 2150, 2152, 2159, 2161, 2162.

8. GARF. F. A-374. Op. 15. Dd. 2215, 2216, 2218.

9. GARF. F. 395. Op. 1. D. 1545.

10. 5 tysyach chlenov MOPRa. Avangard. 1939, 18 Jun., p. 2.

11. Grubyy postupok direktora. Avangard. 1939, 10 Oct., p. 4.

12. Narushenie trudovogo zakonodatelstva. Avangard. 1939, 10 Oct., p. 4.

13. Net poryadka v stolovoy. Avangard. 1940, 30 Mar., p. 2.

14. Nochnoe uchenie. Avangard. 1941, 29 Apr., p. 2.

15. Besporyadki v uchebnom kombinate. Avangard. 1941, 19 Apr., p. 2.

16. Ekonomicheskoe obrazovanie aktiva promkooperatsii. Avangard. 1941, 31 May, p. 2.

17. Vnov organizovannaya Gzhelskaya keramiko-farforovaya proftekhshkola Mosoblpromsoveta obyavlyaet nabor. Avangard. 1940, 20 Nov., p. 4.

18. Loginov V. M., Skalskiy Yu. P. Eta zvonkaya skazka - Gzhel. Moscow: Svarog, 1994. 191 p.

19. Sidorov I. V. Zdanie Gzhelskogo tekhnikuma na sluzhbe zashchitnikov Moskvy v 1941 godu. In: Sotsiogumanitarnye nauki i sotsialnye tekhnologii: perspektivy, prioritety i prognozy. Proceedings of International scientific-practical conference. St. Petersburg: Professionalnaya nauka, 2019. Pp. 26-31.

20. Kiselev A. G., Solovyeva S. N., Batenchuk D. M. Uchashchiesya Gzhelskogo tekhnikuma, 1947-1957 gg.: monogr. Gzhel: Izd-vo GGU, 2016. 288 p.

21. Vospominanie veterana. Gzhel. 1991, No. 5-6, p. 3.

22. Obyavlen priem v Gzhelskiy silikatno-keramicheskiy tekhnikum upravleniya promkooperatsii pri SNK RSFSR. Avangard. 1944, 20 Aug., pp. 2.

23. Gzhelskaya professionalno-tekhnicheskaya shkola obyavlyaet nabor. Avangard. 1946, 10 Aug. (No. 120), p. 2.

24. Grigoryeva N. S. Khudozhestvennaya keramika Gzheli i Skopina v sobranii Gosudarstvennogo Russkogo muzeya: katalog. L.: Iskusstvo, 1987. 150 p.

25. Arkhiv GGU. Kniga prikazov Gzhelskogo tekhnikuma za 1946 g. "Vsem klassnym rukovoditelyam tekhnikuma..."

26. Arkhiv GGU. Kniga prikazov Gzhelskogo tekhnikuma za 1946 g.: No. 18, 02.02.1962.

Сухова Элина Константиновна, кандидат исторических наук, старший научный сотрудник, Гжельский государственный университет

e-mail: suhovae@mail.ru

Sukhova Elina K., PhD in History, Senior Researcher, Gzhel State University

e-mail: suhovae@mail.ru

Сидоров Иван Вадимович, преподаватель колледжа, Гжельский государственный университет e-mail: nit123@yandex.ru

Sidorov Ivan V., Lecturer, Gzhel State University

e-mail: nit123@yandex.ru

Статья поступила в редакцию 30.06.2020

The article was received on 30.06.2020 